\title{
Afroperspectividade no ensino de filosofia: possibilidades da Lei 10.639/03 diante do desinteresse e do racismo epistêmico
}

\author{
Afroperspectivity in the philosophy teaching: \\ the Lei $10.639 / 03$ possibilities before \\ the nonchalance and epistemic racism
}

\section{Resumo}

No presente artigo pretendemos percorrer com a leitora e o leitor uma trilha reflexiva tripla: sobre os efeitos da reprodução e perpetuação cultural do racismo epistêmico no ensino de filosofia; sobre os esforços antirracistas que culminaram no Brasil na promulgação da Lei 10.639/03 e da Lei 11.645/08, acrescentando diretrizes importantes em todos os niveis de nosso sistema educacional. E, por fim, a Afroperspectividade, como uma abordagem teórico-metodológica relevante para combater o racismo epistêmico no ensino de filosofia.

Palavras-chave: Educação; Filosofia; Afroperspectiva.

\footnotetext{
* Doutor em Filosofia pela UFRJ, professor de Filosofia da UFRRJ, professor do Programa de Pós-Graduação de Filosofia (PPGFil) da UFRRJ, do Programa de Pós-Graduação em Educação, Contextos Contemporâneos e Demandas Populares (PPGEduc), do Programa de Filosofia e Ensino (PPFEN) do CEFET-RJ. E-mail: renatonoguera@ymail.com

** Doutorando do Programa de Pós-Graduação de Filosofia da Uerj. E-mail: valtermoreira2@gmail.com.

*** Professor de Filosofia da Rede Pública do Estado do Rio de Janeiro, Mestre em Filosofia e Ensino pelo PPFEN/CEFET-RJ. E-mail: ribeirofth@gmail.com.
}

Recebido em: 14/04/2019 Aceito em: 02/12/2019 


\begin{abstract}
In this paper we aim to go alongside the reader through a threefold reflexive path: The first one is over the reproduction and prolongation effects of epistemic racism in Brazilian philosophical education, the second path is through the resilience of the American Indigenous and African descendent which culminated at Brazil the promulgation of both the Lei 10.639/03 and the Lei 11.645/08, which added important guidelines inside of our educational system at all its levels. Thus, the proposal of Afroperspectivity as a pedagogical methodology which allows a Brazilian renunciation of the epistemic racism in Philosophy teaching.
\end{abstract}

Keywords: Education; Philosophy; Afroperspectivity.

\title{
Introdução
}

Não escrevo contra alguém ou contra algo. Para mim, escrever é um gesto absolutamente positivo: dizer o que se admira e não combater o que se detesta. Escrever para denunciar é o mais baixo nível de escrita. Em contrapartida, é verdade que escrever significa que algo não vai bem no estado da questão que se quer abordar. Que não se está satisfeito. Então eu diria: escrevo contra ideias prontas. Escrevemos sempre contra ideias prontas. ${ }^{1}$

A citação acima dá uma dimensão do nosso propósito: é terminantemente proibido curvarmo-nos às ideias prontas. De forma alguma podemos nos submeter a algo estabelecido como verdadeiro por força dos hábitos, tampouco recusar alguma ideia por conta de pouca familiaridade com ela. Talvez, investindo naquilo que é propriamente filosófico, a questão "o que nos faz pensar?" pode ser revitalizada autenticamente a partir do momento que não nos restringimos às ideias prontas, isto é, ao que nos é familiar. O que nos faz pensar? Aqui vale a pena parafrasear dois pensadores franceses: "qual a melhor maneira de seguir grandes filósofos, repetir o que eles disseram, ou então fazer o que eles fizeram, isto é, criar conceitos para problemas que 
mudam necessariamente?"2 Os problemas são o que nos interessa. O que nos faz pensar? São as questões. Não devemos nos esquecer de colocá-las e recolocá-la de tantas maneiras e modos que for preciso. Uma pergunta precisa ser trabalhada sem pudor algum. As interrogações que atravessam este texto podem ser divididas por famílias. A primeira diz respeito ao modo de filosofar: de que maneira podemos filosofar? O que é a filosofia? Qual a sua origem? A partir da problematização da hipótese mais requintada da história da filosofia, nós procuramos retomar questões que pudessem causar desconforto no "senso comum clássico da filosofia". Ora, estamos falando de uma afirmação que se tornou um axioma, cuja falsa autoevidência parou de ser interpelada pela natureza crítica da filosofia. Estamos falando da origem grega da filosofia.

Pois bem, é sabido que o exercício filosófico é incompatível com dogmas irrefutáveis. Consideramos importante reforçar a perspectiva de que a filosofia é uma área sem respostas consensuais. Por isso, defendemos que o apego dogmático às ideias é um obstáculo ao próprio fazer filosófico. E, sem dúvida, filosofia não é terreno para ideias prontas. O nosso percurso pretende lançar luzes sobre uma abordagem filosófica que tem sido trabalhada desde o início da década por um grupo de pessoas da área. A afroperspectividade é a nossa base teórico-metodológica, cujo ponto de partida é perguntar exaustivamente se os argumentos para que a certidão de nascimento da filosofia seja lavrada em cartório grego são realmente fiéis aos acontecimentos. Não seria um caso de adoção? Não seria um caso de registro indevido? Ou ainda, a maneira como perguntamos não nos induz a uma formulação equívoca da resposta? A partir de incursões afroperspectivistas, vamos investigar o problema do racismo epistêmico presente no ensino de filosofia, analisar a implantação da Lei 10.639/03 como a alternativa mais adequada para que o ensino de filosofia realize seus objetivos políticos, epistemológicos, éticos e estéticos. Outra interrogação diz respeito ao desinteresse de estudantes do ensino médio pela escola e, ainda mais especificamente, pelas aulas de filosofia.

\section{Referencial teórico: Afroperspectividade}

O que é afroperspectividade? Uma abordagem filosófica que tem como referências a afrocentricidade, o quilombismo e o perspectivismo ameríndio. O artigo intitulado Denegrindo a filosofia: o pensamento como coreografia de 
conceitos afroperspectivistas deu-nos as primeiras pistas de formulação dessa abordagem. O ponto de partida foi uma série de questões colocadas a partir da hipótese de que a Grécia é o berço da filosofia. Para os pensadores Gilles Deleuze e Félix Guattari, "a filosofia foi uma coisa grega, embora trazida por migrantes. Para que a filosofia nascesse, foi preciso um encontro entre o meio grego e o plano de imanência do pensamento" ". Os dois franceses concordam com os alemães Hegel e Heidegger na concepção deque a Grécia e a filosofia possuem uma relação fundamental "como o ponto de partida de uma história interior ao Ocidente, de modo que a filosofia se confunde necessariamente com sua própria história" ${ }^{2}$. E, a partir da problematização de origem, estabelecemos uma revisão bibliográfica, que nos permitiu trazer à luz visões que circulam com baixa frequência em ambientes acadêmicos, fundamentadas por um vasto material que aponta para a diversidade de hipóteses sobre o nascimento da filosofia.

A afroperspectividade não postula algo inédito. Não se trata de abandonarmos a tradição filosófica ocidental, mas, de retomá-la criticamente e considerar outras escolas como fundamentais para um franco, profundo e fértil debate filosófico. Daí a inclusão de nomes que influenciam os estudos afroperspectivistas como o filósofo da Martinica, Frantz Fanon, uma inspiração transversal a ser ressaltada quando o assunto é a afroperspectividade. Fanon traz uma questão de suma importância: um deslocamento do eixo europeu para o pensamento. "A África não é apenas o lugar a partir do qual Fanon pensa. É o próprio tema desse pensamento, bem como a sua matéria. E é à

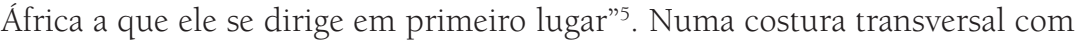
Fanon, a afroperspectividade é devedora da afrocentricidade, sistematizada por MolefiAsante ${ }^{6}$, o perspectivismo ameríndio de Tânia Stolze Lima ${ }^{7}$, quilombismo de Abdias do Nascimento ${ }^{8}$, assim como os estudos contra-coloniais do pensamento afro-pindorâmico do filósofo Antônio Bispo dos Santos ${ }^{9}$.

\footnotetext{
3 DELEUZE, G; GUATTARI, F. 2001, p. 122.

4 Idem, p.124.

5 MBEMBE, A. 2012, p.5

6 ASANTE, M. 2000.

7 LIMA,T. 2011.

8 NASCIMENTO,A. 1980.

9 SANTOS, A.2015.
} 
De modo bastante resumido, a afroperspectividade lança mão de categorias-chave da afrocentricidade, a saber: localização e agência, propondo uma articulação ontológica por meio do perspectivismo ameríndio e operando com elementos afro-pindorâmicos e quilombistas.

De modo algum, excluímos a Europa, embora considerando que filosofar não deixa de ser uma atividade interpretativa. A nosso ver, a origem da filosofia é uma interpretação. Pois bem, quando o assunto é interpretação, Foucault nos ajuda: "O princípio da interpretação, não é outra coisa que o intérprete"10. A interpretação tem que interpretar a si mesma, a autoria de quem interpreta, suas fontes, o que está sob e sobre os olhares. Daí consideramos que a filosofia não pode escapar ao seu caráter de interpretação. Não podemos deixar de pensar que a interpretação é sempre plural. Não pode existir uma só interpretação filosófica a respeito de um problema. Mesmo que as coincidências existam, é preciso suspeitarmos e fazermos sempre o que é próprio da vocação filosófica: entrevistar incessantemente o problema, recolocá-lo.

A afroperspectividade nasceu da obsessão de se entender a origem da filosofia. Num exercício de investigação historiográfica, nossas incursões encontraram versões em dissenso que não tinham um ponto de partida comum. Em geral, quando o assunto era o desacordo sobre a origem da filosofia, encontrávamos algo como o milagre grego versus condições históricas e culturais de emergência, ou ainda variações dessa versão. Em todos os casos, a "nacionalidade" grega da filosofia já estava dada como certa. A esse respeito não se colocava desconfiança alguma. Primeiro porque a palavra "filosofia", sendo grega, implicaria a não existência de uma atividade antes de ser nominada. Em nossas interrogações afroperspectivistas, cabem as questões: será que não existiam palavras para "filosofia" em outras culturas? Uma palavra inaugura uma atividade? A atividade é nomeada antes ou depois de existir? Somos surdos e cegos para ouvirmos e enxergarmos o que está fora da nossa cultura? Esta cegueira se dá por conta de nosso etnocentrismo?

\section{Racismo epistêmico, manuais e textos consagrados}

Os textos filosóficos, sejam eles consagrados ou não, devem ser examinados sem receio de que nossas convicções sejam abaladas. Após uma série de estudos oriundos de uma revisão bibliográfica e a metodologia do estado da 
arte, percebemos algo que merece destaque. O Programa Nacional do Livro Didático (PNLD) de Filosofia de 2018 ampliou o número de obras indicadas. $\mathrm{Na}$ edição anterior eram apenas cinco livros. Além dos títulos Filosofando: Introdução à Filosofia, de Maria Lucia de Arruda Aranha e Maria Helena Pires Martins; Iniciação à Filosofia: Ensino Médio, de Marilena Chauí; Filosofia: experiência do pensamento, de Silvio Gallo; Fundamentos da Filosofia, de Gilberto Cotrim e Mirna Fernandes; Filosofia: por uma inteligência da complexidade, de Celito Méier. A estes somaram-se, em 2018: Reflexões: filosofia e cotidiano, de José Antônio Vasconcellos; Filosofia: temas e percursos, de João Vergílio Cuter, Luiz Repa, Marco Valentim, Paulo Vieira Neto, Roberto Bolzani Filho e Vinicius de Figueiredo; Diálogo: primeiros estudos de filosofia: existência de sentido, de Juvenal Savian Filho. Aqui nosso objetivo não é uma incursão analítica sobre estes oito livros. Porém, vale destacar que, apesar da diversidade de abordagens, todos celebram, seja de modo pouco ou muito crítico, a Grécia como berço da Filosofia. Em nenhuma das obras encontramos uma diversidade de opiniões quando o assunto é o "nascimento" da filosofia.

Os estudos de historiadores da filosofia como o congolês Theopile Obenga, o português José Nunes Carreira e o italiano Robert Bernasconi apontam para o que aqui vamos denominar de "ponto cego" da origem da filosofia. Sem dúvida, por "ponto cego" podemos entender uma expressão polissêmica que pode assumir sentidos diferentes nos mais variados contextos; mas, de maneira genérica remete a uma região de invisibilidade. Assim, o que aqui denominamos ponto cego da (origem da) filosofia é a exclusão de hipóteses divergentes daquela que está presente nos manuais e textos de autores consagrados.

"Um dos modos talvez menos polêmicos de caracterizar a filosofia é através de sua história: forma de pensamento que nasce na Grécia antiga por volta do séc. VI a.C."11. Será a história da filosofia realmente impassível de polêmica? Os pensadores franceses Gilles Deleuze e Félix Guattari dizem: “(...) a filosofia foi uma coisa grega (...). Para que a filosofia nascesse foi preciso um encontro entre o meio grego e o plano de imanência do pensamento"12. Nós estamos diante do ponto cego. Pois bem, se uma área escapa à visibilidade, um bom mapeamento ficará comprometido. 
A partir de diversos estudos ${ }^{13}$, podemos dizer que o eurocentrismo é a fonte da cegueira e o redutor dos limites do reconhecimento humano da realidade. A História da filosofia apresenta muitos aspectos invisíveis. Ainda que um tema filosófico seja considerado por uma comunidade de propagadores e produtores como um cânone, esse tema não pode ficar fora do exame crítico-filosófico, o que implica uma "maior consciência das tradições da filosofia que vão além da assim chamada filosofia ocidental, com sua origem na Grécia"14.

O trabalho de historiografia filosófica feito pelo italiano Robert Bernasconi ressalta a existência de elementos étnico-raciais na filosofia, o que não invalida o fato de que a filosofia tenha algo a dizer qualquer pessoa, independentemente de sua tradição cultural. "O problema surge quando uma filosofia quer se dirigir a todos e, no processo, silencia ou ignora vozes alternativas" ${ }^{\prime 5}$. A observação de Bernasconi é bastante relevante, assim como afirmam Diop e Bernal; trata-se de uma crítica a uma mudança de comportamento no contexto historiográfico. Inúmeros dados a respeito dos textos filosóficos africanos permanecem pouco estudados. Esse fenômeno é denominado como racismo epistêmico, ou ainda, epistemicídio:

Os conquistadores da África durante as injustas guerras de colonização se arrogaram a autoridade de definir filosofia. Eles fizeram isto cometendo epistemicídio, ou seja, o assassinato das maneiras de conhecer e agir dos povos africanos conquistados. O epistemicídio não nivelou e nem eliminou totalmente as maneiras de conhecer e agir dos povos africanos conquistados, mas introduziu, entretanto, - e numa dimensão muito sustentada através de meios ilícitos e "justos" - a tensão subsequente na relação entre as filosofias africana e ocidental na África. ${ }^{16}$

O epistemicídio perpetrou uma desqualificação estética, ética, intelectual e espiritual de todos os povos não-europeus. Afinal, além do domínio e colonização dos corpos e das terras, os europeus se esforçaram por efetivar o

13 JAMES, G. 1954; 1967; 1977. DIOP, C, 2005. BERNAL, M 1988. BERNASCONI, R, 2007. OBENGA, T. 2004. ASANTE, M, 2000.

14 BERNASCONI, R, 2007, p. 612.

15 Idem, 2007, p.611

16 RAMOSE, 2011, p. 09 
domínio e a colonização da informação e do conhecimento. Todos esses processos estabeleceram relações assimétricas que favoreceram a discriminação negativa e a desqualificação das produções intelectuais dos povos africanos e de seus descendentes ${ }^{17}$. Foram sucessivos ataques que criaram essa perspectiva de ausência de filosofia fora da Europa.

Embora já se tenha demonstrado de forma suficiente que tais concepções são frutos de preconceitos e erros de pensamento, elas permanecem sendo entendidas de forma hegemônica como legítimas e justificáveis. Os livros didáticos de filosofia carregam a comum e quase unânime proposição de que o pensamento filosófico surgiu no contexto grego por volta do século $\mathrm{V}$ a. E. C. e, mesmo os autores e as autoras que recusam a tese em descrédito do "milagre grego", fazem coro para dizer que condições históricas, sociais e culturais fizeram da Grécia, o berço da filosofia. Essa perspectiva engendra uma cultura que estabelece uma proibição arbitrária a qualquer posicionamento crítico diante da questão, configurando esse tema como um verdadeiro tabu.

Estamos diante de um fenômeno que tem sido denominado de "tabu da filosofia". Esta expressão conceitual foi desenhada na esteira de trabalhos como o de George James, em O legado roubado, assim como A filosofia antes dos gregos, de José Nunes Carreira.

Ora, os argumentos que buscam sustentar a exclusividade grega precisam ser revisitados. De modo que se reconheça pelo menos a existência de perspectivas paralelas e o equívoco de desconsiderar argumentos. De maneira geral, tal como nos diz o filósofo camaronês Achille Mbembe, estamos diante do "alterocídio, isto é, a constituição do outro não como semelhante a si mesmo, mas como objeto propriamente ameaçador, do qual é preciso se proteger"18. Um aspecto do alterocídio é o racismo epistêmico. Por esta expressão conceitual entendemos: um conjunto de dispositivos, práticas e estratégias que produzem cânones que deixam de fora o que não é da matriz europeia. O crivo eurocêntrico para o conhecimento recusa a validade das justificativas feitas a partir de referenciais não europeus, quer sejam eles filosóficos, culturais, históricos, ou científicos, distinguindo o que é conhecimento válido e o que não é conhecimento. De tal maneira que para preencher os critérios filosóficos específicos que diferenciem a filosofia de outros modos de saber, uma construção intelectual precise estar sempre articulada, ou mantendo algum tipo de diálogo, com pressupostos e temas erigidos pelos gregos. De acordo

17 MOORE, 2008.

18 MBEMBE, 2018, p.27 
com Obenga, não é raro que a produção relativa ao antigo Egito tenha sido difundida por meio de abordagens superficiais e sem apresentação de fontes, na maioria das vezes fetichizadas, romantizadas e "europeizadas", embranquecendo as imagens da nobreza e das divindades.

Não vamos apontar em que momento preciso o conhecimento filosófico kemético foi "marginalizado" e "esquecido". Estima-se como fato relevante a queima da biblioteca de Alexandria por volta do século $\mathrm{VI}^{19}$, em cuja destruição, as produções científicas e filosóficas do Kemet, durante o período entre a Idade Média e a Renascença, passaram por um processo de invisibilização através do qual ficaram à margem da dita História Universal da Humanidade. Mas o problema envolve inevitavelmente o racismo em sua dimensão epistêmica e a injustiça cognitiva advinda do projeto de colonização perpetrado pela Europa, responsáveis pela tentativa de apagar sistematicamente a produção intelectual africana e em outros continentes.

O filósofo queniano Dismas Masolo problematiza a ideia de racionalidade, situando as pessoas em duas categorias: (1) as "monorracionais", isto é, aquelas habituadas a usarem apenas um modelo de racionalidade, e (2) as "polirracionais", isto é, aquelas que usam dois ou mais modelos de racionalidade. Disso podemos constatar que o modelo de racionalidade ocidental tem sido privilegiado indevidamente em relação aos outros modelos, o que gera desconforto e indisposição nas pessoas monorracionais, quando confrontadas com outros modelos de racionalidade.

Assim, enquanto o reconhecimento das filosofias, cujos modelos de racionalidade não se baseiam nos modelos ocidentais, não faz parte do horizonte de possibilidades da Concepção Hegemônica de filosofia, o pluriversalismo e a polirracionalidade reconhecem a humanidade de todos os povos dentro de uma perspectiva pluriversal, segundo a qual todos os saberes emergem de contextos culturais específicos e podem, por conta de seu caráter humano, ser validados em outros contextos culturais.

Considerando essa definição de filosofia, podemos encontrar textos filosóficos antigos em várias regiões do mundo. No Kemet, por exemplo, Amenemope, que viveu na última fase da 20ª Dinastia do Reino Novo (1186-1069), escreveu uma obra que encontramos na íntegra no Papiro 1074 do Museu Britânico, datando aproximadamente de 1300 a.E.C. Sidarta Gautama (563483 a. E. C.) teve suas apresentações orais compiladas por discípulos. Lao-Tsé, que viveu no século VI a. E.C., é considerado o autor do Tao-Te-King. Na 
mesma China Confúcio (551-479 a. E.C.) nos deixou os Analectos. Mogobe Ramose realiza reflexões a partir da perspectiva ubuntu, pensamento filosófico que compreende as dimensões epistemológica, ontológica e ético-política. No aspecto epistemológico, a filosofia ubuntu reivindica a polirracionalidade (existem modelos diversos de racionalidade), isto é, não podemos trabalhar com um modelo único de razão. Do ponto de vista ontológico, reivindica o reconhecimento do "ser" como pluriversal ao invés de universal. O pressuposto é de que existem vários universos simbólicos e culturais coexistindo e se interpelando mutuamente. No aspecto ético-político a palavra é interdependência. Nós sempre estamos numa relação com outras pessoas, com outros animais, com vegetais, com o meio ambiente em que vivemos.

Além de textos escritos, concordamos com o filósofo Joseph Omeregbe ${ }^{20}$, para quem, a respeito da autoria em diversas regiões do planeta, a falta de registros escritos "não significa que eles não tenham existido; nós temos fragmentos de suas reflexões filosóficas e suas perspectivas foram preservadas e transmitidas por meio de outros registros escritos como mitos, aforismos, máximas de sabedoria, provérbios tradicionais, contos e, especialmente, através da religião".

É interessante considerar que Omoregbe não desvincula a filosofia da religião ${ }^{21}$, reconhecendo que sistemas religiosos têm invariavelmente elementos filosóficos. Aqui consideramos que, guardadas as devidas proporções e medidas, encontramos semelhanças em textos de várias regiões do mundo na Antiguidade. Neste sentido, intelectuais ameríndias(os) têm colocado em foco o que denominam de filosofia Andina, trazendo à luz elementos do pensamento presente na cultura do povo Inca. O mesmo pode ser aplicado aos resíduos de registros nos hieróglifos dos Maias e pictogramas dos Astecas, sem falar nos registros gráficos do povo Olmeca que, segundo Caterina Magni, ${ }^{22}$ trata-se de ideogramas. Também precisamos mencionar o pluriverso cultural dos 305 grupos étnicos indígenas que habitam o território brasileiro desde que este se chamava Pindorama ${ }^{23}$. Conforme diversas pesquisas têm

20 OMOREGBE, 1998, p. 74

21 De acordo com Robert Bernasconi, na Europa a separação entre filosofia e religião ocorre no período moderno.

222014.

23 Pesquisas no âmbito da História e Cultura dos Povos Indígenas têm convergido para a ideia de que o local de chegada das naus portuguesas era denominado pelos tupinambás que ali viviam de Pindorama, terra das palmeiras. 
confirmado a existência de uma tradição filosófica nesses povos, vale registrar dois exemplos que contam essa história, além de proporem conceitos atuais e contemporâneos: $1^{\circ}$ ) Davi Kopenawa ${ }^{24}$ com A queda do céu nos apresenta aspectos significativos do pensamento filosófico yanomami; $2^{\circ}$ ) Daniel Munduruku, ${ }^{25}$ com formação acadêmica nas áreas de filosofia e Educação, nos brinda com a história da filosofia do povo Munduruku em Banquete dos deuses. No continente africano o vasto material de versos Iorubas antigos é muito rico e tem sido revisitado por inúmeras filósofas africanas e vários filósofos africanos contemporâneos. Com o livro Socrates and Orunmila: two patrons saints classical philosophy, a filósofa nigeriana Sophie Oluwoletraz traz à cena acadêmica uma bela pesquisa apontando semelhanças entre Sócrates e Orunmilá, o filósofo iorubano anterior ao pensador grego. O filósofo também nigeriano, Siriku Salami, em parceria com a brasileira Ronilda Iakemi Ribeiro, publicou o livro Exu e a Ordem do Universo. Nessa obra encontramos riquezas minuciosas de conceitos iorubanos desmistificando interpretações vulgares e, com bastante vigor, apresentando o sistema filosófico com ênfase na ética.

\section{Desinteresse de estudantes do ensino médio e o caso da filosofia}

Uma reflexão sobre as dificuldades de se ensinar filosofia na educação básica precisa analisar de forma detida o desinteresse dos estudantes. Trata-se, pois, de um problema que atinge todas as disciplinas do ensino médio, sem exceção. É o que demonstra os dados de uma pesquisa do Centro Brasileiro de Análises de Planejamento (CEBRAP), encomendada pelo Ministério da Educação (MEC). Conforme o relatório:

A pesquisa qualitativa pretendeu investigar que tipo de relação que os jovens estabeleceram com a escola de Ensino Médio que frequentam (ou que frequentaram) e qual o sentido que a escola e os conteúdos que compõem o quadro curricular têm na [...] vida deles. [Conforme o relatório] por essa metodologia, [buscou-se] [...] um instrumento que permitissem aos jovens falarem sobre a vida, suas paixões, bem como sobre os sentidos da escola e do lugar que ela ocupa em suas prioridades e em sua rotina. Essa etapa

24 KOPENAWA, D; ALBERT, B, 2015.

25 MUNDURUKU, D. 2000. 
do trabalho foi elaborada a partir da coleta de dados por intermédio de diferentes métodos: participação de jovens em grupos focais; entrevistas em profundidade; e observação virtual, acompanhando veículos de sociabilidade e diálogos entre jovens na internet, como redes sociais e fóruns de discussão sobre escola e adolescência. ${ }^{26}$

A pesquisa, que ouviu cerca de 1000 jovens de baixa renda com idades entre 15 e 19 anos nas cidades de São Paulo e Recife, revelou que a maioria dos jovens ouvidos não reconhece a utilidade do conteúdo das disciplinas nas aulas. Conforme o relatório (2013), não obstante o fato de matérias mais canônicas como Português e Matemática serem relativamente bem aceitas, o mesmo não pode ser dito de disciplinas do campo das ciências exatas como Química e Física e também das disciplinas ligadas à área das Humanidades e Ciências Sociais, como Geografia, Filosofia e, Sociologia e Literatura. O relatório (2013) aponta que, enquanto 78,8\% e 77,6\% consideram Língua Portuguesa e Matemática, respectivamente, as áreas do conhecimento mais úteis, 36\% dos entrevistados consideram Geografia, História e Biologia descartáveis. E apenas $19 \%$ consideram Literatura importante. Filosofia foi considerada importante por $24,9 \%$. Segundo o relatório, a construção dessas categorias no questionário quantitativo foi produzida a partir da narrativa dos participantes da pesquisa qualitativa, em que o sentido de uma disciplina era associado ao uso instrumental dos seus conteúdos no cotidiano dos estudantes ${ }^{27}$. É uma breve digressão que ajuda a contextualizar as salas de aula. Mas, aqui, não vamos avançar em investigar hipóteses que desnudem os porquês do desinteresse; interessa-nos trazer, por exemplo, o debate acerca do repertório de debates filosóficos, oferecido pelo material didático ser praticamente todo ocidental. Em poucas obras encontramos alguma menção a textos que não sejam de autores do sexo masculino e brancos. Pretendemos, portanto, contribuir com a discussão sobre a ausência de perspectivas africanas no ensino de filosofia, o que nos leva a refletir acerca da interferência do racismo epistêmico na História da filosofia. A partir de diversos estudos como, por exemplo, os livros Racismo: uma questão de todos nós (NOGUERA, 2018), Racism in a Racial Democracy: The Maintenance of White Supremacy in Brazil (TWINE, 2000) e O que é Racismo Estrutural? (ALMEIDA, 2018), somos capazes de perceber que

26 TORRES, 2013, p. 67.

27 Idem, p. 103 
na sociedade brasileira o racismo é institucional e estrutural. Portanto, não se trata simplesmente de preconceito interpessoal, ou ainda, de circunstâncias pontuais de discriminação, mas, sim, de uma estrutura política, econômica, cultural e histórica que permeia toda a sociedade, e que, desta forma, não se pode desconsiderar sua preponderância em todos os setores da sociedade.

Como já afirmamos, tratar do racismo é tratar de um sistema complexo, de caráter estrutural: as instituições, por conta de um histórico longamente construído, reproduzem determinadas práticas de exclusão, muitas vezes sutis $^{28}$. Essas práticas que, embora sutis, contribuem para a perpetuação da exploração e exclusão produzidas pelo racismo na sociedade brasileira, por estarem nela diluídas, seriam capazes de influenciar de forma diversa as relações sociais estabelecidas e, neste sentido, contribuir com a indiferença dos alunos em relação às aulas de filosofia, por exemplo. Mas se trata de uma hipótese difícil de ser confirmada sem uma análise da influência do racismo sobre o processo de ensino-aprendizagem como um todo, dentre outras questões pertinentes, que precisariam ser analisadas. Tendo em vista esse fato, propomos que sejam feitas, de forma preliminar, análises sobre as influências do racismo epistêmico sobre as diversas perspectivas de ensino de filosofia já consolidadas e amplamente praticadas no Brasil. Uma das nossas hipóteses é a de que o racismo é um componente que interfere profundamente no modo como a filosofia entra em sala de aula. Principalmente por conta de uma perspectiva que desconsidera o espaço (psicológico e cultural), como destacamos nas primeiras seções deste trabalho e ressaltaremos nas seções seguintes.

\section{Aspectos legais}

A inclusão do ensino de filosofia no Ensino Médio brasileiro como disciplina obrigatória foi homologada no ano de 2008, e seu processo foi gradativo. Em 2003, o Estado brasileiro ratificou um longo processo de formulação do Movimento, a promulgação da Lei 10. 639/03. No início apenas três disciplinas faziam parte da obrigatoriedade de se incluírem conteúdos de História e Cultura Afro-Brasileira e Africana: Artes, História e Literatura. Nas Diretrizes Curriculares Nacionais para o ensino de História e Cultura Afro-Brasileira e Africana, em 2006, foram publicadas as Orientações Curriculares Nacionais

28 NOGUERA, 2018, p. 33. 
para o Ensino Médio (OCNEM). No ano de 2008 veio o Plano Nacional para Implementação das Diretrizes Curriculares Nacionais para o ensino de História e Cultura Afro-Brasileira e Africana, e no mesmo ano foi incluída a Cultura e História dos Povos Indígenas com a Lei 11.645/08.

Um problema permaneceu latente desde a promulgação da Lei 10.639/03: o ensino de filosofia era apenas sugerido e, mesmo com as regulamentações do ensino de filosofia presentes nas leis 4.024/61, 5.692/71 e 7.044/82 e após a reforma da LDB em 1996, a disciplina passava a fazer parte do currículo diversificado do Ensino Médio, conforme deliberação dos Conselhos Estaduais de Educação e sua efetivação era facultada às Federações nacionais e seus Conselhos Educacionais, ou tinham apenas um assunto particular integrado nas disciplinas de Geografia, História ou Literatura; Em 2008, como resultado das articulações do povo indígena brasileiro, é promulgada a Lei 11. 645/08, que altera a 10. 639/03, incorpora seus elementos e é lançado o Plano Nacional para Implementação das Diretrizes Curriculares Nacionais para Educação das Relações Étnico-Raciais, segundo o qual toda a população brasileira é responsável pela promoção do combate ao racismo. Ambas as leis instituíram a mudança do Art. 26-A da Lei 9.394/96 da LDB, estabelecendo que os estudos de História e Cultura Afro-Brasileira, Africana e Indígena são obrigatórios em todas as modalidades de ensino e níveis de educação. E o Art. 36 da Lei 9.394/96 recebe um novo inciso preconizando a obrigatoriedade do ensino de Filosofia e Sociologia durante todo o Ensino Médio. Em 2009, todas as escolas de Ensino Médio inseriram a disciplina Filosofia no $1^{\circ}$ ano; em 2010, no $2^{\circ}$ ano; em 2011, passou a integrar todas as séries desse nível de ensino.

Embora a Lei 10.639/03 tenha sido substituída formalmente pela Lei 11.645/08, interpretamo-la como registro político indicador de um marco legal e ponto de inflexão histórica e política nascido de uma agenda do movimento negro. Assim, por opção política e pedagógica, consideramos a Lei 10.639/03 como um marco simbólico e político da luta contra o racismo no Brasil. De qualquer modo, apesar das diversas reformas legais na Educação Básica, o ensino de filosofia não pode se esquivar a operar com os conteúdos de História e Cultura Afro-Brasileira, Africana e dos Povos Indígenas. O caráter indutor da Lei ajuda profundamente que o cotidiano escolar das aulas de filosofia seja impelido a trazer questões que estão fora dos manuais. 


\section{Conclusões parciais: a afroperspectividade no ensino de filosofia}

No campo da filosofia também estão a emergir, gradualmente, reflexões em torno do modo como as ideias sobre a espacialidade modelaram o pensamento filosófico. Durante demasiado tempo, a disciplina da filosofia agiu como se o lugar geopolítico e as ideias referentes ao espaço não passassem de características contingentes do raciocínio filosófico. Evitando, e bem, o reducionismo das determinações geográficas, os filósofos têm tido tendência para considerar o espaço como algo demasiado simplista para ser filosoficamente relevante. De facto, exigem outras razões relevantes para explicar a alergia ao espaço enquanto fator filosófico provido de significado. Há questões referentes ao espaço e às relações geopolíticas que enfraquecem a ideia de um sujeito epistêmico neutro, cujas reflexões não são mais do que a resposta aos constrangimentos desse domínio desprovido de espaço que é o universal. Tais questões também põem a descoberto as formas como os filósofos e os professores de filosofia tendem a afirmar as suas raízes numa região espiritual invariavelmente descrita em termos geopoliticos: a Europa. ${ }^{29}$

O filósofo porto-riquenho Nelson Maldonado-Torres contribui para um debate filosófico acerca do espaço. Não se trata de revisitar Kant, o espaço como um a priori das condições de possibilidade do conhecimento. Mas, um debate filosófico-político que analisa as injustiças advindas do espaço como modulador do pensamento. Maldonado-Torres insiste em dizer que alguns espaços monopolizam o direito ao pensamento sofisticado, o que torna muitos pensamentos invisíveis. A afroperspectividade pode ser dita como um projeto de fazer visíveis as filosofias que brotam de espaços, lugares e territórios que foram colonizados. Afroperspectividade é um convite para que possamos problematizar a espacialidade, sob inspiração do filósofo Franz Fanon, autor da tese de doutorado reprovada Pele negra e máscaras brancas. Fanon é um importante precursor e influenciador, propondo a descolonização do pensamento radicalmente na obra Os Condenados da Terra.

Frantz Fanon é um nome central nos estudos culturais, pós-coloniais e africano-americanos, seja nos Estados Unidos, na África ou na Europa. Falamos muitas vezes de estudos fanonianos, tal o volume de estudos que têm a

29 MALDONADO-TORRES, 2008, p. 72. 
sua obra como objeto de reflexão. Meus colegas e alunos negros brasileiros devotam a ele a mesma admiração, respeito e devoção que seus irmãos de cor africanos e do hemisfério norte. No entanto, quando busquei material para escrever este artigo, deparei-me com um silêncio impactante, em revistas culturais ou acadêmicas, que perdurou até meados da década de 1960. ${ }^{30}$

O que pode uma filosofia afroperspectivista no ensino médio? Essa é nossa questão. Ora, pode nos provocar a pensar, encontrando possibilidades pouco frequentadas com conceitos que circulem pouco no circuito curricular. Não cabe definir um papel central para a filosofia. Mas, inevitavelmente o fazemos, seja explicitamente ou nos pressupostos de nosso fazer filosófico. Daí a afroperspectividade ter como proposta a promoção de um debate no ensino médio em favor da pluriversalidade ontológica, em favor de uma epistemologia polirracional e de ética da interdependência. A demanda de conteúdos obrigatórios de História e Cultura Afro-Brasileira, Africana e dos Povos Indígenas em todas as disciplinas é razão necessária e suficiente para inclusão da filosofia afroperspectivista em sala de aula. O início é justamente demonstrar que a origem da filosofia não precisa ficar restrita a uma única versão.

\section{Referências}

ALMEIDA, Silvio Luiz de. O Que É Racismo Estrutural? MG: Letramento, 2018.

ALVES, Marcos Alexandre. Desafios e potencialidades: o ensino de filosofia no cenário da educação básica brasileira. Revista Sul-Americana de Filosofia e Educação. Número 21: nov/2013-abr/2014, p. 157-169.

ASANTE, MolefiKete. Afrocentricity: the theory of social change. 3a. ed. Trenton: Africa World, 1988.

BERNAL, Martin. Black Athena: the Afroasiatic Roots of Classical Civilization, tomes I, New Brunswick: Rutgers University Press, 1988.

BRASIL. Lei de Diretrizes e Bases da Educação Nacional. Lei número 9394, 20 de dezembro de 1996. 
BRASIL. Lei $N^{o} 10.639$, de 9 de janeiro de 2003. Altera a Lei no 9.394, de 20 de dezembro de 1996, que estabelece as diretrizes e bases da educação nacional, para incluir no currículo oficial da Rede de Ensino a obrigatoriedade da temática "História e Cultura Afro-Brasileira", e dá outras providências. Diário Oficial da União, Brasília, DF, 10 jan. 2003a, p. 01. Disponível em: <http://www.planalto.gov.br/ccivil_03/ Leis/2003/L10.639.htm/>. Acesso em: 19 de janeiro de 2019.

BERNAL, Martin. Black Athena: the Afroasiatic Roots of Classical Civilization, tomes II, New Brunswick: Rutgers University Press, 1991.

BERNASCONI, Robert. "Etnicidade, cultura e filosofia". In: BUNNIN, Nicholas e TSUI-JAMES, E. P. (org.) Compendio de Filosofia. Trad. Luiz Paulo Rouanet. 2. ed. São Paulo: Edições Loyola, 2007. p.611- 625.

CARREIRA, José. A Filosofia antes dos Gregos. Lisboa: Publicações Europa-América/ Mem-Martins, 1994.

CONCEIÇÃO, José Maria Nunes Pereira. África: um novo olhar. Rio de Janeiro: CEAP, 2006. Compendio de Filosofia. Trad. Luiz Paulo Rouanet. 2. ed. São Paulo: Edições Loyola, 2007. p.611- 625

DELEUZE, G; GUATTARI, F. O Que É Filosofia? Trad. Bento Prado Jr. E Alberto Alonso Muñoz. RJ:34, 1992

FANON, Frantz. Os condenados da terra. Tradução de Enilce Albergaria Rocha, Lucy Magalhães. Juiz de Fora: UFJF,2006.

FOUCAULT, Michel. Nietzsche, Freud e Marx. In FOUCAULT, M. Nietzsche. Cahiers de Royaumond. Paris: Les Édition de Minuit, 1967, p. 189.

GUIMARÃES, Antonio Sergio. Cor e Raça. In SANSORE, Livio, PINHO, Osmundo Araújo (Orgs) Raça: novas perspectivas antropológicas. 2. ed. Rev. Salvador: Associação Brasileira de Antropologia, EDUFBA, 2008.

JAMES, George G. M. Stolenlegacy: the greek philosophy is a stolen egyptian philosophy. Drewryville: Khalifah's, 2005.

KOHAN, Walter O. Filosofia: caminhos para seu ensino. Rio de Janeiro: Lamparina, 2008, p. 72

KOPENAWA, Davi; ALBERT, Bruce. A queda do céu: palavras de um xamã yanomami. São Paulo: Cia das Letras, 2015.

LIMA, Tânia Stolze. Por uma cartografia do poder e da diferença nas cosmopolíticas ameríndias. Revista de Antropologia, São Paulo, USP, 2011, v. 54, n. 2, pp.601-646.

MALDONADO-TORRES, Nelson.A topologia do Ser e a geopolítica do conhecimento. Modernidade, império e colonialidade. Revista Crítica de Ciências Sociais, 80, março 2008, p. 71-114.

MARCONDES, Danilo. Iniciação à história da filosofia. $2^{\text {a }}$ ed. Rio de Janeiro: Jorge Zahar; 1997.

MASOLO, Dismas. Filosofia e conhecimento indígena: uma perspectiva africana. In SANTOS, Boaventura; MENESES, Maria Paula. Epistemologias do sul. Tradução e revisão por Margarida Gomes. São Paulo: Cortez, 2010. 
MBEMBE, A. Crítica da razão negra. Trad. Sebastião Nascimento. São Paulo: n-1 edições, 2018.

MBEMBE, Achille. A universalidade de Frantz Fanon, Art Africa (Lisboa), 2012, p.05. Disponível online: http://artafrica.letras.ulisboa.pt/uploads/ docs/2016/04/18/5714de04d0924.pdf (acessado em 30/03/2015)

MBEMBE, Achille. Crítica da razão negra. Trad. Sebastião Nascimento. São Paulo: n-1 edições, 2018.

MBEMBE,Achille.A universalidade de Frantz Fanon, Art Africa (Lisboa), 2012, p.05. Disponível online: http://artafrica.letras.ulisboa.pt/uploads/ docs/2016/04/18/5714de04d0924.pdf (acessado em 30/03/2015)

MOORE, Carlos. A África que incomoda: sobre a problematização do legado africano no quotidiano brasileiro. Belo Horizonte: Nandyala, 2008

MUNDURUKU, Daniel. Mundurukando. São Paulo: Ed. do Autor, 2010.

NAVIA, Ricardo. Ensino médio de filosofia nas presentes condições culturais e sociais de nossos países. In KOHAN, Walter O. Filosofia: caminhos para seu Ensino. Rio de Janeiro: DP\&A, 2004. p. 69-84

NASCIMENTO, Abdias. Quilombismo: documentos de uma militância pan-africanista. Petrópolis: Vozes, 1980

NOGUERA, Renato. Racismo: uma questão de todos. Rio de Janeiro: Fundação Roberto Marinho, 2018.

OBENGA, Théophile. AncientEgyptand Black Africa. Chicago: Karnak House, 1992.

OMOREGBE, Joseph. African Philosophy: yesterday and today. In: EZE, Emmanuel Chukwudi (Org.). AfricanPhilosophy: ananthology. Oxford: Blackwell, 1998.

OLUWOLE, Sophie. Socrates and Orunmila: Two Patron Saint of classical Philosophy. $3^{a}$ ed. Lagos: Ark Publishers, 2017.

TORRES, Haroldo da Gama et. al. O que pensam os jovens de baixa renda sobre a escola: Projeto de pesquisa desenvolvido pelo CEBRAP com o apoio da Fundação Victor Civita. São Paulo, 2013, p. 67. Disponível em: <https://www.walmartbrasil.com.br/wm/ wp-content/uploads/2015/07/O-que-pensam-os-jovens-de-baixa-renda-sobre-a-escola.pdf/>. Acesso em: 25 de fevereiro de 2019.

TWINE, Francine Winddance. Racism in a Racial Democracy: The Maintenance of White Supremacy in Brazil. New Jersey: Rutgers University Press. Edição do Kindle, 2000.

RAMOSE, Mogobe.Globalização e ubuntu In SANTOS, Boaventura; Meneses, Maria Paula. Epistemologias do Sul. Tradução: Margarida Gomes. São Paulo: Cortez, 2010.

SANTOS, Antônio Bispo. Colonização, Quilombos. Modos e Significações. Brasília: Instituto de Inclusão no Ensino Superior e na Pesquisa, 2015.

SÀLÁMì, Síkírù (King); RIBEIRO, Ronilda Iakemi. Exu e a ordem do universo. 2. Ed. São Paulo: Oduduwa, 2015. 